Energy, competition and innovation: how policies' coordination may contribute to a new energy model

Eduardo Teixeira Isabel Salavisa

2013

WP n. ${ }^{\circ} 2013 / 10$

DOCUMENTO DE TRABALHO

WORKING PAPER

DINAMIR'CET

soctirios

FCT

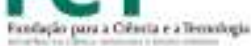


Energy, competition and innovation: how policies' coordination may contribute to a new energy model

Eduardo Teixeira*

Isabel Salavisa**

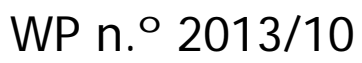

DOI: 10.7749/dinamiacet-iul.wp.2013.10

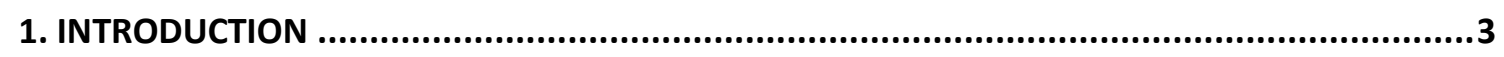

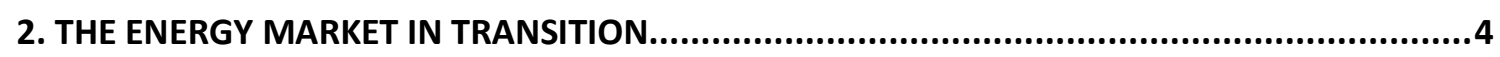

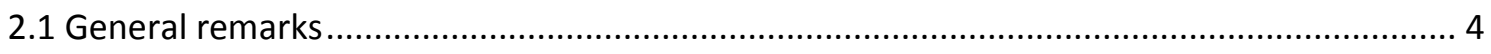

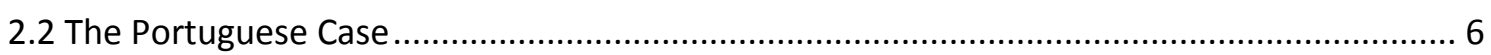

3. COMBINING THE TWO PERSPECTIVES: COMPETITION AND INNOVATION ........................11

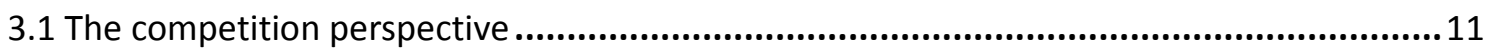

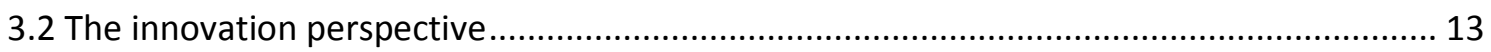

3.3 The interplay between market concentration and innovation performance....................... 14

4. EVIDENCE ON COMPETITION AND INNOVATION IN ENERGY........................................... 15

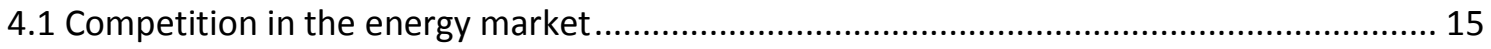

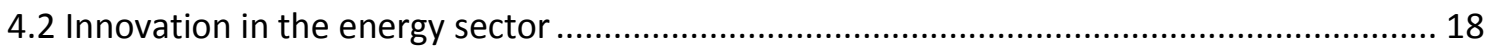

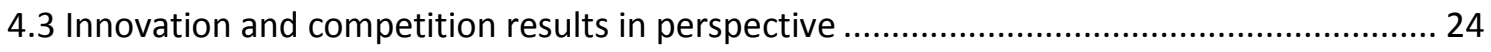

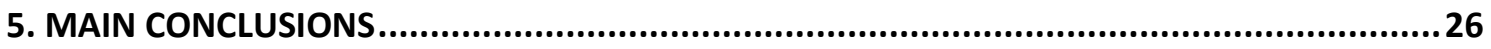

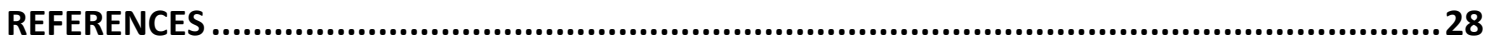

*ERSE, Rua Dom Cristóvão da Gama, 1 - 3. , 1400-113 Lisbon, Portugal - Phone: 351213033 240;

E-mail: eteixeira@erse.pt.

**ISCTE-IUL, DINÂMIA-CET-IUL, Av. Forças Armadas, 1649-026 Lisbon, Portugal - Phone: 351210464031

E-mail: isabel.salavisa@iscte.pt. 


\title{
Energy, competition and innovation: how policies' coordination may contribute to a new energy model $^{1}$
}

\begin{abstract}
The aim of this paper is to shed light on the role played by the coordination of public policies - competition and innovation policies - in achieving a new organizational model in the energy sector. The acknowledgement that the use of energy represents a main issue in today's world, due to its impact on the sustainability of global resources, is the central driver for the current debate.

Taking investment in the renewables energy sector as a proxy to innovation, the paper shows that policies coordination is likely to promote a swifter transition to a new energy system. The paper is focused on the electricity industry and market in Portugal, but its main assertions are likely to apply to other European countries and to other network industries.
\end{abstract}

Keywords: energy sector; renewable energies; innovation policy; competition policy; policy coordination

JEL Codes: O30; Q55; Q20; L40; L50; L38.

\footnotetext{
${ }^{1}$ A preliminary version of this paper has been presented at the EAEPE Conference on "Schumpeter's heritage: the evolution of the theory of evolution", October 27-30, 2011, Vienna, Austria.

DINÂMIA'CET - IUL, Centro de Estudos sobre a Mudança Socioeconómica e o Território ISCTE-IUL - Av. das Forças Armadas, 1649-026 Lisboa, PORTUGAL

Tel. 210464031 - Extensão 293100 E-mail: dinamia@iscte.pt www.dinamiacet.iscte.pt
} 


\section{INTRODUCTION}

The aim of this paper is to shed light on the role played by the coordination of public policies in achieving a new organizational model in the energy sector. The acknowledgement that the use of energy represents a main issue in today's world, due to its impact on the sustainability of global resources, is the central driver for the current debate.

In developed countries, namely in the European Union, in which the electricity and gas sectors use huge transmission and distribution infrastructures (grids), the model of the vertically integrated monopolistic company has been in transition towards a competition approach. In fact, and partly as a consequence of technological change, these activities are now treated as regulated natural monopolies, allowing at the same time generation and retailing activities to be fully opened to competition.

This paper is focused on the electricity industry and market in Portugal, but its main assertions are likely to apply to other European countries and to other network industries. Recent developments in the electricity industry showed two main trends in Europe: a relative success in the vertical unbundling of activities, together with the persistence of an almost unchanged horizontal concentration; and a decrease in direct R\&D expenditure. As to the Internal Energy Market Directives, they have set the relevant principles of the organization of the industry across EU, which are common to electricity and natural gas.

In policy terms, the change in the organization of the energy industry is taking place by combining a market efficiency approach (competition policy approach) with a long run dynamic efficiency approach (innovation policy approach). Although there is a general consensus on the fact that an effective strategy to redesign industry has to take into account the interdependencies of both approaches and aim at coordinating them in a coherent policy framework, academic research in this area is still relatively scarce.

Due to the dramatic changes underway, with the emergence of a totally new area of renewables and its implications (system coordination, smart grids, electric vehicles), the measure of innovation cannot rely upon the conventional indicators based on $R \& D$ expenditure alone. Rather, it has to draw on the investment in the new generation renewable energies. Thus, in this paper the renewables deployment is considered as the most adequate proxy for innovation in the sector and as the main focus of an innovation policy.

Consequently, it focus on the policy schemes that support the shift towards renewables (feed-in tariffs, tax reductions), which are based to a large extent in environmental and technological externalities.

The research in this paper follows some recent developments in the study of structural change in the energy sector organization (see Jamasb and Pollitt, 2008; Nakada, 2005; Marques, 2005) 
along with the research more oriented to innovation policies in the field (see Sagar and Zwan, 2005; Gallagher, 2006; Markard and Truffer, 2006; Buen, 2005). The methodology consists of the critical assessment of policy results, both in market competition and industrial innovation.

Our main conclusions point to the lack of evidence of a deterministic effect of competition policies, especially the model of liberalization, in the success of innovation policies in the energy industry. Nevertheless, some positive scale effects could be identified, suggesting that more concentrated market structures, through higher revenues, might affect innovation in a positive way. A positive effect of government actions in innovative activities is also suggested.

Conversely, the impact on competition of innovative renewable oriented policies is not clear-cut in a European perspective, although in cases such as Spain or Portugal an increased competition, through lower market concentration, has been achieved alongside with the development of renewables. Drawing on the Iberian case, the paper concludes that policy coordination in the fields of innovation and competition may have a positive impact in promoting a new energy model.

\section{THE ENERGY MARKET IN TRANSITION}

\subsection{General remarks}

The use of energy represents in today's world one of the main issues in human behaviour, with important consequences on the sustainable use of global resources. After World War II, the use of energy grew significantly and represented a major role in economic growth, both in developing countries and leading economies.

Until the 1970s, energy consumption grew almost with no restrictions, since price signals and externalities had not a significant influence on consumption decisions. However, in the beginning of the last quarter of the 20th century, the oil shocks and the emerging discussion on limited energy resources and the global consequences of energy consumption on climate change moved the discussion of strategic energy industry organization to a turning point.

Economies strongly dependent on energy consumption for economic growth were particularly exposed to geopolitical crises in energy sourcing and also to the consequent macroeconomic effects in their trade balance. This fact, together with environmental concerns, gave a new momentum to endogenous and renewable energy resources in the context of the energy industry redesign. New energy strategies oriented to sustainable growth are now a driver and a consequence of technological innovation. Likewise, process innovations are faced as a way to promote efficiency in the energy industry.

Although this change applies to the energy industry as a whole, the sectors with a higher dependency on network infrastructures were the ones to be in the spotlight during the 
restructuring process, due to their monopolistic structure. In fact, in the electricity and gas sectors in developed countries, namely in the European Union, which use massive transmission and distribution infrastructures (grids), the model of vertically integrated monopolistic companies has been in transition to a competition approach in activities which are not natural monopolies. The electricity market, due to its own characteristics and broader consumption impacts - non storable, lower substitution elasticity and necessary resource for a significant part of the economic activity -, is a clear-cut example in the energy restructuring process.

The process of redesign of the energy industry towards liberalization was historically initiated in Chile and later adopted in the OECD countries with different motivations ${ }^{2}$ and timeframes. In the context of European Union, the United Kingdom played the pioneering role in the liberalization process, also known as deregulation.

One of the main characteristics of deregulation was the vertical unbundling of activities once performed by a single company in a regional or national monopoly framework. The rationale was to separate those activities in which the market is not economically the more efficient approach from those that can benefit from competition. Due to the heavy investments needed and a cost structure which is scale determined, network activities are identified as natural monopolies ${ }^{3}$, whereas generation and supply activities are considered competition areas.

Another element of the liberalization process in energy is the adjustment in the role of government in the industry: from a general model of state owned monopolistic companies to one in which the government acts as regulator and not as a direct market participant.

Therefore, the energy industry restructuring process (Nakada, 2005), in particular in electricity, is relying on the following main characteristics:

- Clear separation of transport and distribution activities, which are considered to be natural monopolies, from generation and supply activities;

- Definition of the concept of third party access (TPA hereafter) to networks, with nondiscriminatory tariffs, commonly set under independent regulated mechanisms;

- Opening the generation and supply activities to competition, with the abolishment of legal barriers to entry.

In this context of vertical unbundling of activities and market opening to competition it is also important to have an assessment of social welfare gains and losses from a new dynamics in the industry. In this sense it is clearly important to ensure that a vertical monopoly structure is not replaced by a new industrial organization in which companies may exert market power and

\footnotetext{
${ }^{2}$ In the United States and Australia the main reasons for the liberalization process relied on the evidence of substantial price differences across States, in particular in the electricity sector; while in Europe the political will to create a single European market also for energy was an important driver, even more relevant than price or efficiency considerations.

${ }^{3}$ Cost structures under natural monopolies have the following property: $C\left(q_{1}+q_{2}\right)<C\left(q_{1}\right)+C\left(q_{2}\right)$, with $C$ being the cost associated to provide $\mathrm{q}_{\mathrm{i}}$. This means that the cost function is sub-addictive.

DI NÂMIA'CET - IUL, Centro de Estudos sobre a Mudança Socioeconómica e o Território ISCTE-IUL - Av. das Forças Armadas, 1649-026 Lisboa, PORTUGAL

Tel. 210464031 - Extensão 293100 E-mail: dinamia@iscte.pt www.dinamiacet.iscte.pt
} 
retain the vast majority of economic surplus, in spite of security of supply, investment levels and innovation. Therefore, the role of public competition policies, enforced by either a sector regulator or a transversal one, should include institutional arrangements and policy coordination devices in order to address global challenges. Clearly, one of main concerns is to ensure a model in which short term market efficiency (a central concept in competition policy) and long term dynamic efficiency (a basic feature of innovation policy) are properly dealt with.

Although some academic discussions and the dominant policy decisions point to the net positive benefit from the unbundling process, another perspective (Nardi, 2010) outlines the need for further economic evidence and proposes an empirical analytical approach to this issue, mainly aiming at global policy coordination, and including concerns with the macroeconomic effects of energy consumption, energy independence and climate change.

\subsection{The Portuguese Case}

As this paper is focused on the electricity market as a pragmatic example of energy restructuring process, and since this process is partly a consequence of the sustainable development debate, the example of Portugal is straightforward. In fact, the Portuguese energy sector is characterized by a dramatic foreign dependency, with consumption relying mainly on fossil fuel usage, with environmental consequences and a substantial impact on the country's trade balance.

Energy policy developments in Portugal, especially in the last 20 years, have been shaped by the European perspective, in which the Directives ${ }^{4}$ for implementing the internal energy market are at the core of policy design.

In 2000, the EU Green Paper on the security of energy supply ${ }^{5}$ set the main strategic objective to “(...) ensure, for the well-being of its citizens and for the proper functioning of the economy, the uninterrupted physical availability of energy products on the market at an affordable price for all consumers, whilst respecting environmental concerns and looking towards sustainable development”. Later on, with the 2020 energy strategy ${ }^{6}$, the set of energy priorities were further detailed with a new focus on energy efficiency in consumption, under a market oriented approach and a concern with competitive prices, along with security of supply and technological leadership. As Europe set a global objective of reducing the energy dependency, improvements in energy usage efficiency were a clear purpose, both in EU policy and member states’ policies, in order to reduce the energy intensity of the economy ${ }^{7}$. Figure 1 shows a significant improvement in European Union global energy efficiency from 1995 to 2008, with distinct

\footnotetext{
${ }^{4}$ For the electricity market see the Directive 96/92/EC, the Directive 2003/54/EC and the Directive 2009/72/EC, all concerning common rules for the internal market.

${ }^{5}$ COM (2000) 769.

${ }^{6}$ COM (2010) 0639.

${ }^{7}$ Ratio between primary energy consumption and gross domestic product or physical output. DINÂMIA'CET - IUL, Centro de Estudos sobre a Mudança Socioeconómica e o Território ISCTE-IUL - Av. das Forças Armadas, 1649-026 Lisboa, PORTUGAL Tel. 210464031 - Extensão 293100 E-mail: dinamia@iscte.pt www.dinamiacet.iscte.pt
} 
evolutions across sectors - impressive in industry, agriculture and services and less significant in transport and households.

Figure 1 - EU-27 Energy intensity by sector and final energy intensity

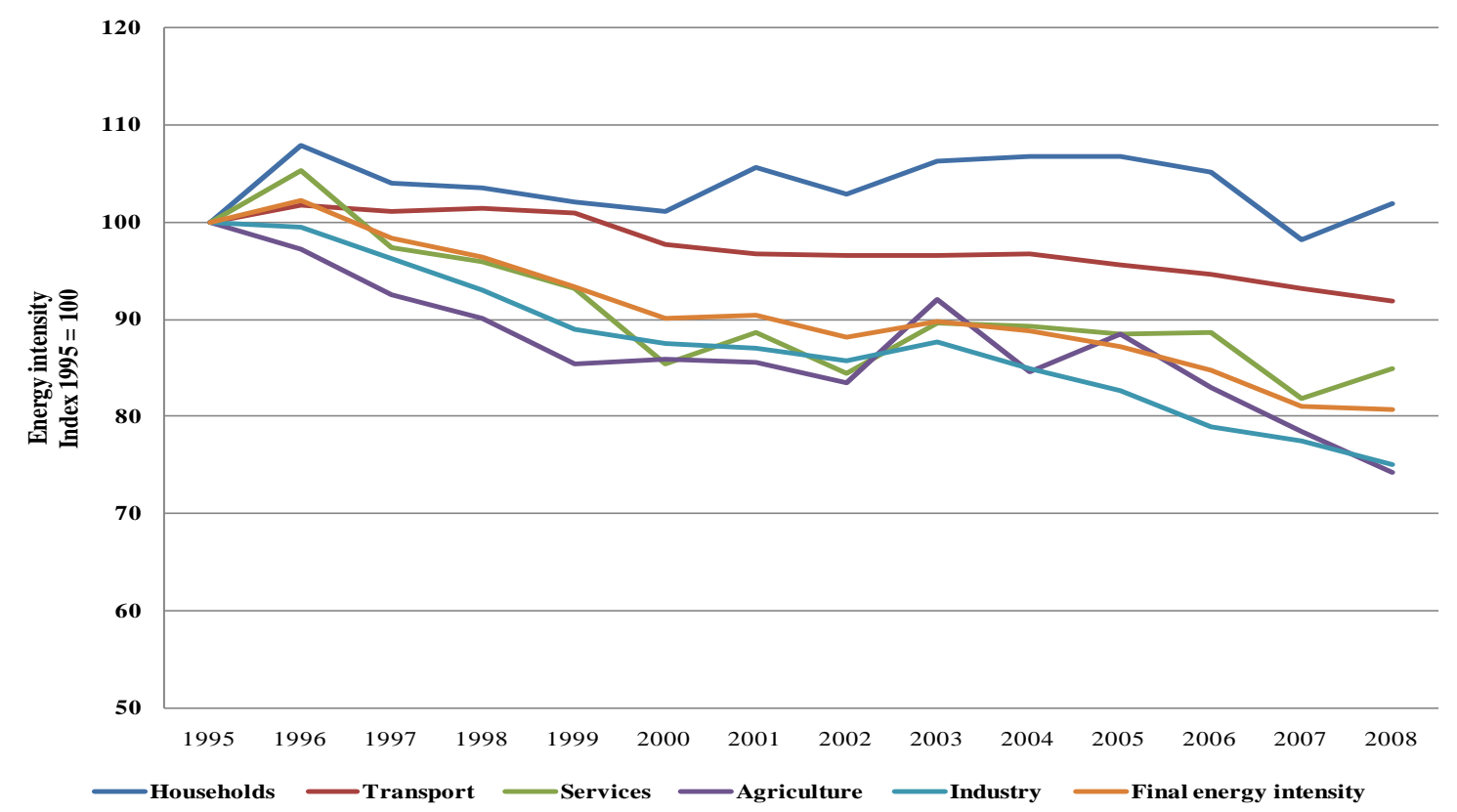

Source: European Environment Agency.

In Portugal, although the global energy policy goals were in line with EU policy targets, the national energy intensity index proved to be diverging from Europe until 2005, remaining slightly unchanged since 1995. The last three years in Figure 2 show an impressive evolution in terms of energy efficiency in Portugal, following policy developments oriented to this objective.

Figure 2 - EU-27, EU-15 and Portugal final energy intensity

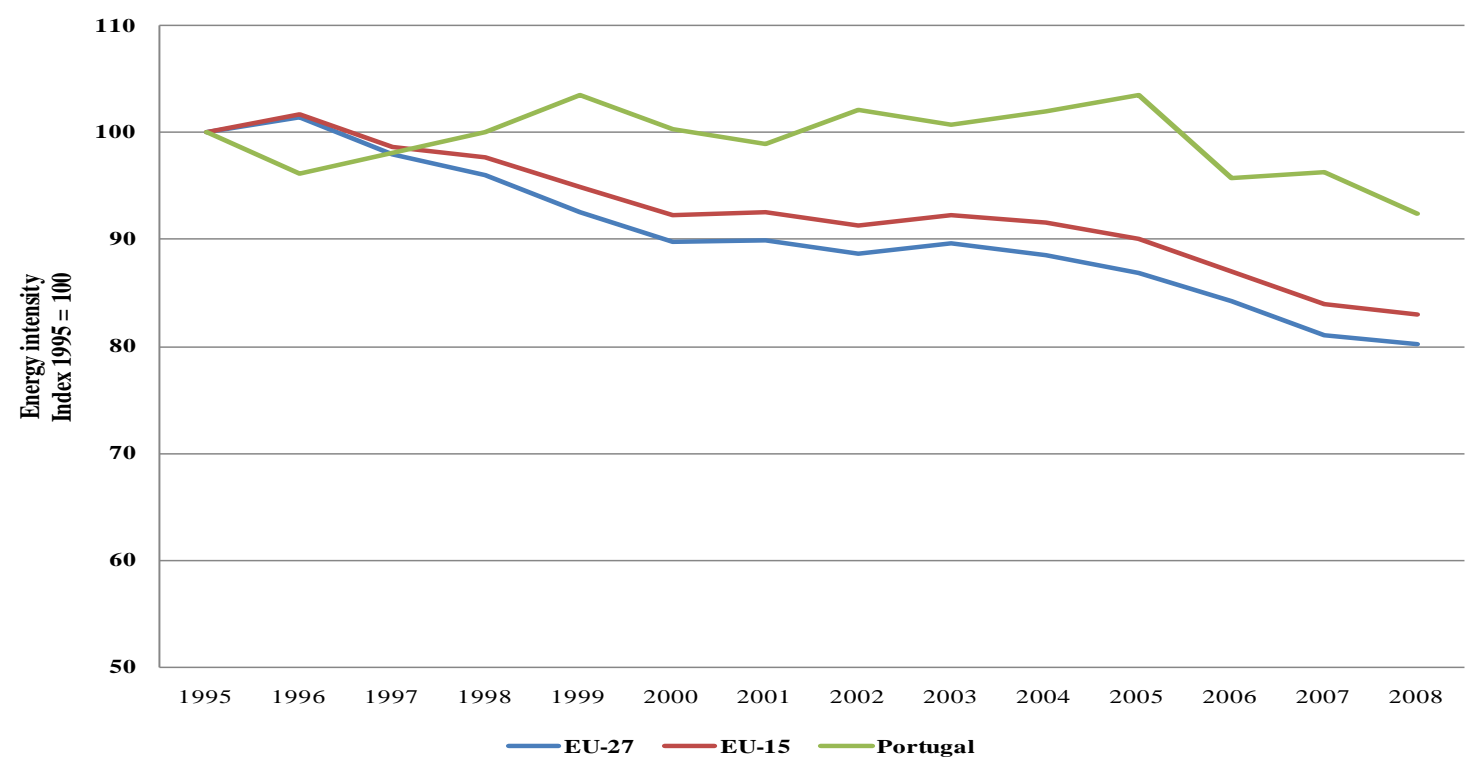

Source: European Environment Agency. 
Figure 3 - Portugal's energy dependency

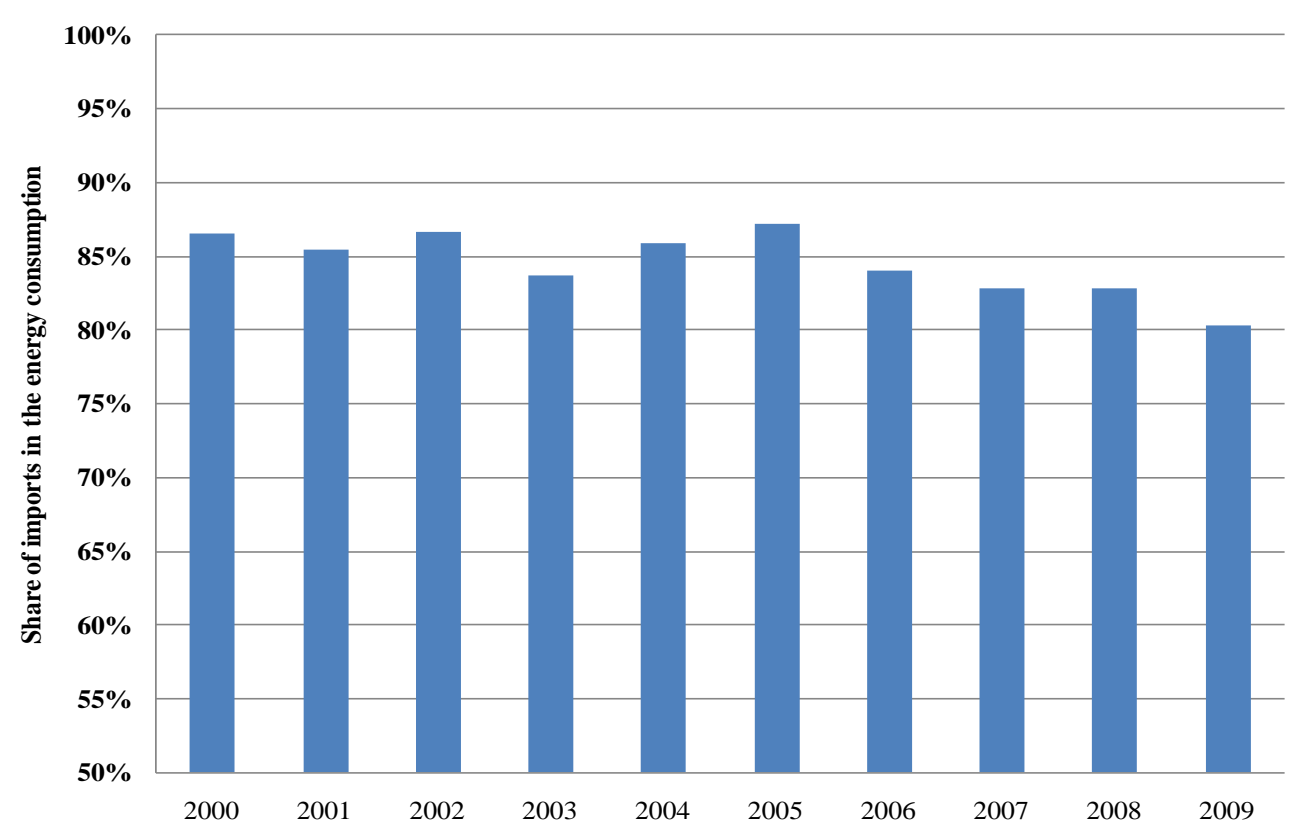

Source: Portuguese National Directorate of Energy (DGEG).

The growth of energy consumption was the main driver of the Portuguese performance in 19952005, namely in the end user subsector, fostering high levels of energy dependency, since the country lacks fuel resources. In fact, apart from hydro electricity generation and other renewable sources, Portugal imports all of the remaining primary energy consumed, the largest share being oil. Figure 3 shows the level of energy dependency of Portugal from 2000 to 2009, with an almost unchanged tendency during the first half of the period and a consistent decline from 2005 onwards.

Major variations in the energy dependency level before 2005 were mostly based on the hydro generation fluctuations due to the annual variance of hydrological regimes. As shown in Figure 4, Portugal adopted a strategy of energy diversification, especially with the introduction of natural gas in the country in the beginning of the 1990s and, afterwards, with a strong political will to ensure higher levels of energy efficiency and a significant penetration of renewable ${ }^{8}$ and endogenous sources. Figure 4 also shows the above mentioned increase of renewable energy sources, along with a decrease in total energy consumption from 2005 onwards, as an indicator of the improvement in the energy efficiency level.

The shift in Portuguese energy mix in the first decade of the 21st century is obtained through a reduction in oil (and coal) contribution to energy consumption, as also clearly revealed in Figure 4.This objective (reduction of oil dependency) was considered one of main targets in the

\footnotetext{
${ }^{8}$ Renewable sources in this classification include traditional hydro electricity generation and new resources such as wind, solar and geothermal power.

DINÂMIA'CET - IUL, Centro de Estudos sobre a Mudança Socioeconómica e o Território 
national energy strategy, pointing to a switch in the energy model towards a more economic and environmentally sustainable energy industry.

In the case of natural gas, its introduction permitted also some improvement in terms both of greenhouse gas (GHG) emissions and environmental sustainability, according to the national compromises under Kyoto, through its lower emissions of carbon dioxide (CO2), and fuel diversification. By the end of the 1990s, a strong investment in gas fired electricity generation plants suited to substitute for old and heavy polluting fuel-oil plants took off, contributing to obtain efficiency gains and lower CO2 emissions.

Figure 4 - Energy consumption by primary source

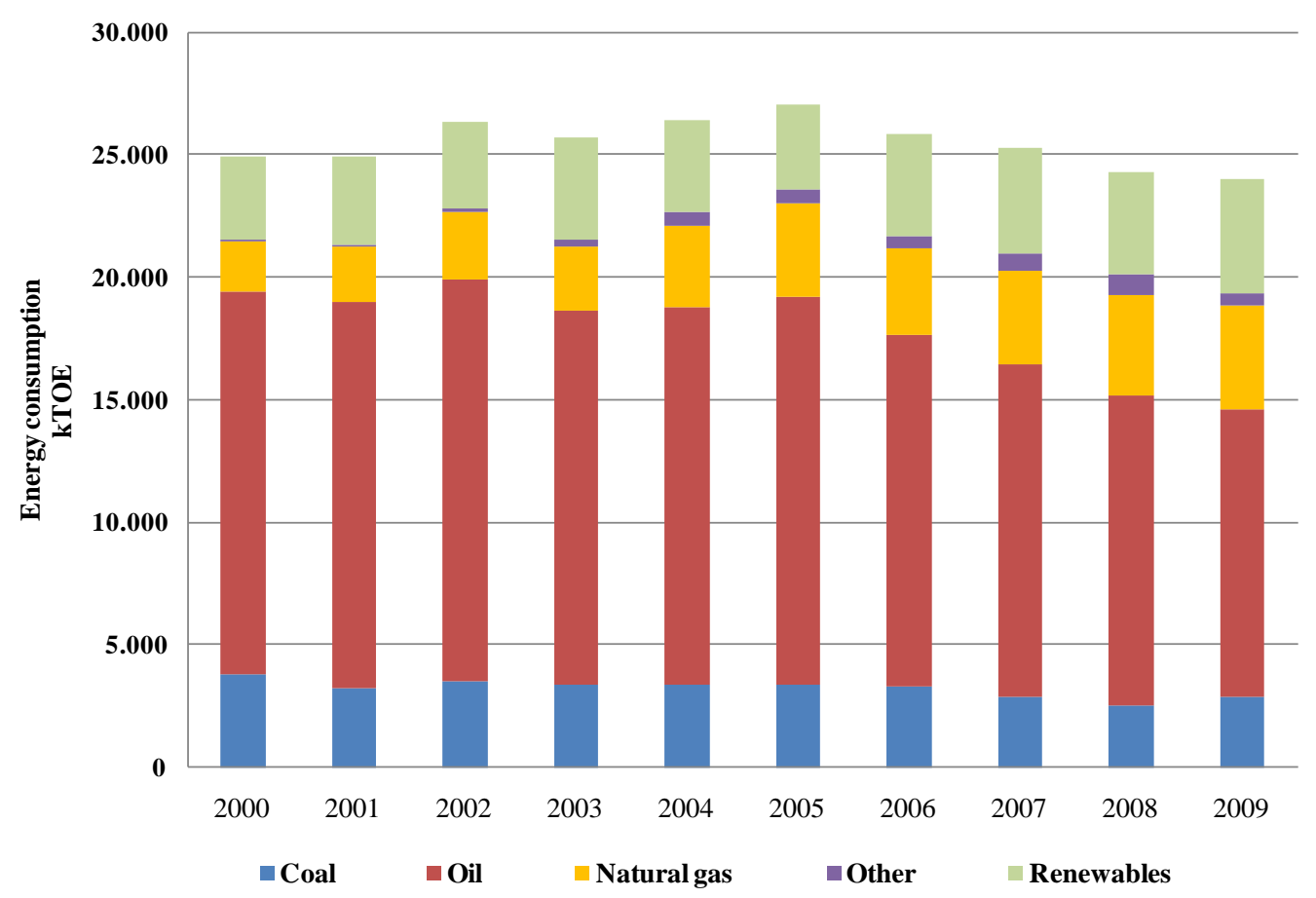

Note: "Other" include net electricity imports and urban residuals. Source: Portuguese National Directorate of Energy (DGEG).

The higher penetration of renewable energy sources is mainly based on wind, which alone accounts for nearly $50 \%$ of the renewable sources growth throughout last decade. This is observable in Figure 5, in which the high volatility of hydro resources availability is also shown, as well as the importance of biomass and biogas in the renewables contribution to consumption.

This is due to a historically important use of wood for household heating purposes, although the introduction of natural gas and solar technology for heating purposes were also intended to reduce its use, due to environmental considerations. 
Figure 5 - Renewable energy sources by type

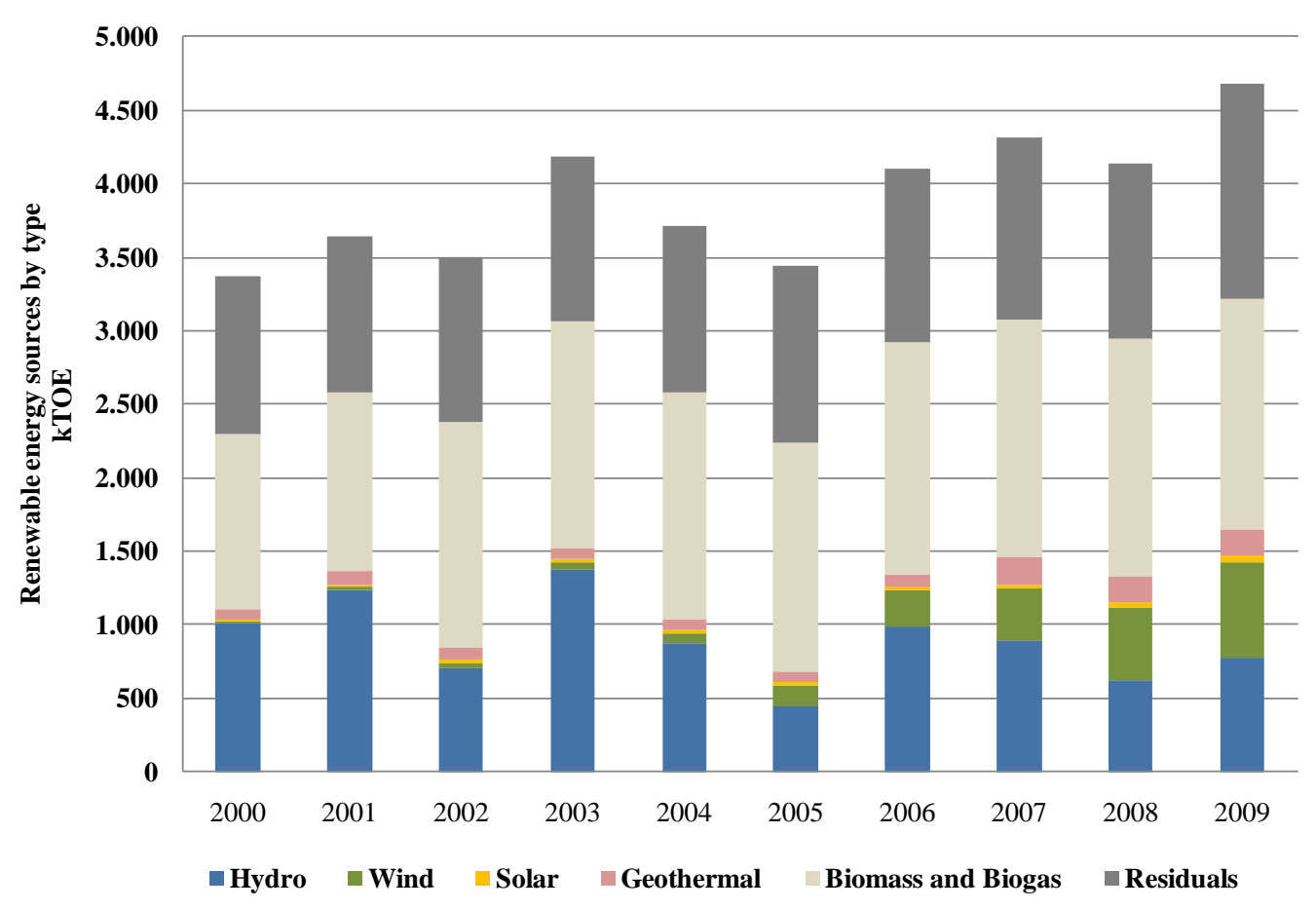

Source: Portuguese National Directorate for Energy (DGEG).

In terms of market arrangements, the Portuguese electricity market follows the framework defined in the Directives for the internal energy market in the EU, with full ownership unbundling of transport network and legal unbundling of distribution networks from the activities of generation and retail supply. The use of networks, either transport or distribution, is ensured in a transparent and non-discriminatory way under the TPA (Third Party Access) principle and with regulated tariffs set by an independent regulatory authority.

Licensing for the generation and supply activities is a legal competence of the government National Directorate for Energy, while economic regulation is a competence of the mentioned independent regulatory authority.

Competition issues follow institutional arrangements under which structural conditions (ex-ante regulation) are mostly set by the energy regulatory authority, following the legal framework, and behavioural aspects of competition are mostly scrutinized by the national competition authority, who also decides on mergers and acquisitions in the industry upon non-binding advice of the energy regulatory authority. 


\section{COMBINING THE TWO PERSPECTIVES: COMPETITION AND INNOVATION}

\subsection{The competition perspective}

Neoclassical competition models adopt a static vision of the efficiency subject since they consider the short run resource allocation for setting the equilibrium.

Perfect competition equilibrium is based on several previous conditions that can be summarized as follows: (i) free entry and exit from the market; (ii) each and all market participants are not able to influence price formation; (iii) all consumers are price takers; (iv) atomicity in both demand and supply side of the market; and (v) homogeneous product and perfect nonasymmetric information. Therefore, to prove the existence of a competitive market equilibrium one should demonstrate that all market participants have no power to affect prices (market power) - which is not a minor task -, analyse entry and exit conditions, verify the atomicity of both supply and demand and, moreover, determine the conditions of substitutability of the product. All these features are part of the market definition.

Since all those preconditions are seldom simultaneously verifiable, imperfect competition is the most common case, and, considering the Pareto's efficiency definition for a perfectly competitive market, the level of efficiency would also be suboptimal. Nevertheless, in some specific situations, perfect competition is not the optimal equilibrium. This is the case of markets with scale effects or the already mentioned presence of sub-addictive cost functions in natural monopolies. Consequently, the geographical scope of the market is a critical part of competition assessments.

Both for legal (license procedure) and economic reasons (a high investment level and the existence of economies of scale), entering the energy market is not totally free and the number of suppliers is usually small. In terms of product substitutability, energy consumption, regardless of its type, is considered to have a low substitution effect, at least in the short run. In fact, switching from one to another energy source, although possible, is time and investment demanding for consumers. This leads to a situation of inelastic demand and price being set by the suppliers.

In addition, there are significant costs associated with transporting energy and often energy sources are located far away from demand and consumption centres, all of this contributing to the relevance of the geographical market definition in energy. In the specific case of electricity, due to its physical characteristics, the substitution effect is even lower and storage is not possible, which implies an even more inelastic demand curve with the price being set by the supply side. In addition, electricity generation is highly centralized and consumption pulverized, leading to the need of network facilities and corresponding transactional costs.

Therefore, energy markets in general, and electricity in a more specific way, are characterized by a monopolistic structure. However, a monopolist structure of the market does not necessarily 
imply a situation of exerted market power, either by the presence of self-regulation or explicit independent regulation of the market. So, the linkage between economic efficiency and perfect competitive markets does not occur in all situations.

A particular case of a monopolistic market structure is the natural monopoly case, in which optimal efficiency level is obtained with a single monopolistic company and not with several competing providers. This takes place in electricity networks, where sunk costs in infrastructure deployment lead to strong economies of scale. Given this feature, free market entry is not viable in network industries such as electricity, and legal procedures reinforce the economic rationale for monopolistic structure.

Nevertheless, the presence of strong economies of scale in part of the value chain does not justify a monopolistic structure in the entire vertical organization of the market and technological changes might erode the fundamentals for a natural monopoly existence.

In electricity markets, the liberalization process started to decompose the vertical organization and identified the distinction between generation and supply activities, on the one hand, and the natural monopoly conceptualization, on the other. This approach, focused on the structural conditions of the electricity industry, is oriented to achieve a higher efficiency in terms of global costs in the sector, once given its static characterization. In fact, the deregulation process's emphasis on competition is specifically focused on reducing barriers to entry the electricity market and foster competition, even in those activities under natural monopoly. In fact, both the legal and ownership unbundling of activities and TPA are basic conditions of deregulation and enable new entrants into the market.

Finally, when assessing competition, not only in the energy industry, it is important to retain how we measure it. Market shares (and the corresponding Herfindahl - Hirschman Index - HHI), number of market participants or the Lerner index, widely in use in the industrial organization literature and also in the electricity market characterization, are suitable to assess the existence of the so-called market power conditions. Since electricity has a quasi-null substitutability in the short run, traditional competition indicators might be considered as good proxies to the effective competition level in this industry. 


\subsection{The innovation perspective}

A dynamic efficiency approach when applied to the electricity industry has led to the debate on how innovation may contribute to a significant change in the organizational paradigm of this market. It is clear from the environmental consequences of energy consumption and the structural dependency of some countries on imported energy that a major shift in the model is to occur.

Since a significant part of the electricity market organization is relying on its technological characteristics, innovation is seen as a decisive contribution to change the energy model. This is so either by reducing barriers to entry (through lower individual investment requirements or new energy sources) or improving the efficiency in electricity generation (higher electricity outcome with the same primary energy input and vice-versa). In the case of electricity, the unfeasibility of large scale storage is another feature that might be addressed by technological change or process improvements, with repercussions in the market structure.

As a result of these technological features and the need for an energy model shift, innovation policy in the industry has a clear rationale and is expected to induce efficiency in the long run. In any case, once the energy industry is far from the perfect information concept, public policy in this area should promote a balanced incentive for $R \& D$ and knowledge dissemination (Sagar and Zwaan, 2005).

As mentioned above, the electricity industry is a technological complex system, both because of the need for real time coordination of decisions or the need to articulate distinct generation technologies. This technological complexity, in addition to the massive investment required to tackle it, contributes to a path-dependency effect in the sector's innovation and new technologies' deployment. In fact, historical analyses of the electricity industry do not provide impressive examples of radical changes in the technological paradigm. More often, innovation is oriented to upgrade existing generation technologies or to introduce new energy technologies along with existing and consolidated ones.

Gallagher et al (2006) have systematized the concept of innovation in the energy industry in the so-called ETI (energy technology innovation) process. Under this process, technological changes contribute to expand the world energy resources and contribute to a sustainable development and policy outcomes are evaluated through a set of proposed fundamental indicators. However, global policy results, as highlighted by Noaillya and Batrakovab (2010) in the specific case of energy-efficient innovations in the Dutch building sector, are also dependent on policies' internal characteristics such as their scope, time consistency and coordination with other policy instruments. Results from the analysis of different policy instruments in the Netherlands in terms of energy efficiency show that discontinuities in other specific policy measures, such as the energy policy, is harmful for innovation in this area. 
The Danish example in promoting new energy sources, extensively analyzed by Buen (2005), is considered to be a sound example of how the policy consistency and coordination endorse better results. A similar analysis carried out for the UK (Foxon and Pearson, 2006) points to the same direction.

Since consistency and coordination of policies are significant factors for policy' results and path-dependencies are present in energy technological improvements, some features of the energy industry restructuring process have a clear-cut impact on ETI. In fact, Markard and Truffer (2006) stressed the fact that the liberalization process is a driver of process and supply side innovation in energy, also contributing to reduce the adverse effect of path dependencies. Their work suggests that the first reaction from incumbents in electricity generation was to resist to innovation, but new challenges brought about by liberalization made them more prone to adopt new management processes and cost reduction efforts and, therefore, to innovate, at least in terms of process innovation.

\subsection{The interplay between market concentration and innovation performance}

The energy market structure itself impacts innovation as well as innovation affects the market structure dynamics. The classical Schumpeterian innovation hypothesis sustains that companies with market power - usually large companies - have higher incentives to innovate, due to a rent seeking behaviour. Artés (2009) performed a cross-industry survey using data for Spanish companies in order to estimate the relationship between market power and innovation. His work delivered some evidence that competition level does affect the decision to promote innovation (through R\&D investment) but is uncertain about the level of investment. This led to the argument that market power will influence long-run decisions but is neutral for short-run ones.

On the other hand, Vives (2008) studies another theoretical assertion, which states the existence of a positive relation between the number of firms and the individual R\&D expenditure. He argues that this is not always true, although empirical evidence also corroborates that in some specific situations an increase in competitive pressure promotes a higher innovation outcome (measured through firms' R\&D effort). This evidence suggests an inverted U-shaped relationship between competition and innovation.

Specifically for the energy industry, the work by Nakada (2005) relating the level of concentration in the energy market with the investment in $R \& D$ for lower carbon dioxide emissions has already suggested the existence of a critical level of market concentration under which $R \& D$ expenditure is maximized. In this sense, the relation between the two variables was suggested to follow the mentioned inverted-U shape. In this regard one might argue that innovation and R\&D expenditure in energy markets are not exactly the same concept, but the 
work of Jamasb and Pollit (2008) clearly stressed that R\&D expenditure represents a central role in innovation for all activities in the electricity industry - from generation to retail supply.

As this paper is focused on the structural market conditions in the electricity industry, features such as those contributing to reduce barriers to entry or unbundling of activities are central in terms of competition policy. This is an approach substantially different from the traditional antitrust competition policy, quite focused on the behavioural aspects of competition. Therefore, we might have two levels of competition policy in the electricity market - market modelling policy (ex-ante competition regulation) and competitive behaviour policy (ex-post competition regulation). Drawing on Vives' paper, we suggest that some specific attention should be paid to variables describing the structural market conditions when assessing competition and, moreover, that inducing competition through the removal of barriers to entry the market should also have a positive impact on the innovation process.

Once considering the structural competition features of the market as the first level of competition policy and taking into account the inverted U-shape relationship between competitive pressure and innovation, acting upon market structural conditions is likely to have a positive effect on innovation. Therefore, the conceptual boundary between market policy and innovation policy might be difficult to be clearly drawn.

\section{EVIDENCE ON COMPETITION AND INNOVATION IN ENERGY}

\subsection{Competition in the energy market}

The deregulation process started in Europe in the mid 1990s has been the main driver of structural changes in the electricity industry. The European Commission (EC) publishes a yearly report on progress in creating the internal gas and electricity markets. In the 2009-2010 report (EC, 2011), the EC concluded the analysis by stressing the existence of "signs which demonstrate the emergence of European energy wholesale markets (...). Nevertheless the situation remains to be improved and significant obstacles to open integrated and competitive markets in electricity and gas remain” (EC, 2011:14).

A significant part of energy markets' deregulation relies on successful market opening up, meaning by this the ability of consumption to freely express its economic preferences. Legal framework for energy internal market has set the date of July 1st 2007 to have all consumers able to freely choose their energy supplier. Some of the Member States, and those included in this analysis, have established the rule of full market opening prior to this date, as demonstrated in Table 1. 
Table 1 - Degree of retail marketing opening (as \% of total retail market)

\begin{tabular}{|c|c|c|c|c|c|c|c|}
\hline & & 2001 & 2004 & 2006 & 2007 & 2008 & 2009 \\
\hline Germany & $\mathrm{DE}$ & 100 & 100 & 100 & 100 & 100 & 100 \\
\hline Denmark & DK & 100 & 100 & 100 & 100 & 100 & 100 \\
\hline Spain & ES & 100 & 100 & 100 & 100 & 100 & 100 \\
\hline France & FR & 37 & 69 & 70 & 100 & 100 & 100 \\
\hline Italy & IT & 70 & 79 & 73 & 100 & 100 & 100 \\
\hline The Netherlands & NL & 63 & 100 & 100 & 100 & 100 & 100 \\
\hline Portugal & PT & 45 & 100 & 100 & 100 & 100 & 100 \\
\hline United Kingdom & UK & 100 & 100 & 100 & 100 & 100 & 100 \\
\hline
\end{tabular}

Source: EC Reports on progress in creating the internal gas and electricity market.

The achievement of legal full market opening does not necessarily mean that market structure has evolved at the same pace. In fact, the degree of market concentration has not changed substantially even in countries with more than ten years of liberalization in retail markets.

Actually, as the EC recognizes in the 2009-2010 report, "at retail level, the integration of the European electricity and gas markets has not developed sufficiently yet. European gas and electricity retail markets are still characterized by substantial disparities in the different Member States as far as price levels and switching rates are concerned” (EC, 2011:14). Table 2 presents the market shares of the three largest retailers, which reveal, for countries with available data, a tendency for maintaining the concentration degree throughout the last decade. That is the case of Portugal, where slight changes have occurred in what concerns retail market structure: the three largest retailers represent more than 95\% of the market from 2001 to 2009, clearly expressing negligible developments in market structure.

It is obvious that market dimension impacts market concentration: large countries (and markets) like Germany or Italy present lower concentration than smaller markets such as Portugal. This brings support to the market integration component of the European energy market policy and explains why most commonly the new entrants in national retail markets are often incumbents in other national markets. 
Table 2 - Market share of the 3 largest retailers (as \% of total retail market)

\begin{tabular}{|c|c|c|c|c|c|c|}
\hline & & 2001 & 2006 & 2007 & 2008 & 2009 \\
\hline Germany & $\mathrm{DE}$ & 50.0 & 46.1 & 40.0 & 52.0 & 47.9 \\
\hline Denmark & DK & 38.0 & NA & NA & NA & NA \\
\hline Spain & ES & 94.0 & 67.5 & 83.9 & 84.8 & 82.7 \\
\hline France & FR & 90.0 & 94.0 & NA & 97.0 & 96.0 \\
\hline Italy & IT & 72.0 & 60.0 & 33.1 & 59.0 & 59.0 \\
\hline The Netherlands & NL & 48.0 & NA & NA & NA & 81.1 \\
\hline Portugal & PT & 99.0 & 98.5 & 99.6 & 99.6 & 95.2 \\
\hline United Kingdom & UK & 42.0 & NA & NA & NA & NA \\
\hline
\end{tabular}

Source: EC Reports on progress in creating the internal gas and electricity market.

On the other hand, since wholesale markets play a decisive role in electricity prices in the retail markets, developments at wholesale level do affect the way retail markets operate. One of the main characteristics of electricity markets in Europe is the significant vertical operation of market participants: companies in the retail market are usually those present in the generation activity and, thus, in the wholesale market. This feature constitutes an important obstruction to competitive markets, since barriers to entry the retail market are built by incumbents through electricity sourcing rigidity.

The evolution of wholesale electricity markets throughout the last 10 to 15 years does not present a significant reduction in market concentration on a national basis, as it is illustrated in Table 3. For that reason, significant effort has been placed in regional market integration as a way to achieve a wider integration at a European level. In that sense, the EC assessment of the internal market in 2010 emphasized that "wholesale electricity markets showed increased integration through market coupling spread to several regions and a greater convergence of wholesale price" during 2009 (EC, 2011:5). Increased "price convergence in the Iberian wholesale market" (EC, 2011: 5) was one of the examples of positive developments mentioned in the EC Report, and this particular feature is important in the case of Portugal and Spain for the simple reason that interconnection between these two electrical systems is significant in relative terms to the total market dimension. 
Table 3 - Market share of the 3 largest generators (as \% of total electricity generation)

\begin{tabular}{|c|c|c|c|c|c|c|c|}
\hline & & 2001 & 2004 & 2006 & 2007 & 2008 & 2009 \\
\hline Germany & $\mathrm{DE}$ & 64.0 & 72.0 & 68.5 & 85.4 & 84.7 & 79.3 \\
\hline Denmark & DK & 78.0 & 40.0 & 75.0 & 75.0 & 75.0 & 75.0 \\
\hline Spain & ES & 83.0 & 74.0 & 60.3 & 76.0 & 72.9 & 79.4 \\
\hline France & FR & 92.0 & 96.0 & 93.0 & 93.0 & 93.0 & 99.0 \\
\hline Italy & IT & 69.0 & 65.0 & 66.3 & 61.2 & 57.6 & 55.6 \\
\hline The Netherlands & NL & 59.0 & 69.0 & 62.0 & 61.0 & 69.9 & 64.0 \\
\hline Portugal & PT & 82.0 & 76.0 & 75.0 & 72.5 & 72.2 & 72.6 \\
\hline$\overline{\text { United Kingdom }}$ & $\overline{\mathrm{UK}}$ & $3 \overline{6.0}$ & $-\overline{39.0}$ & $\overline{37.5}$ & $-\overline{41.0}$ & $4 \overline{2.0}$ & $4 \overline{6.0}$ \\
\hline
\end{tabular}

Source: EC Reports on progress in creating the internal gas and electricity market.

Following what has been mentioned on the descriptive value of some indicators used in competition assessments, one should also take into account the level of market concentration in wholesale electricity markets, when measured through market shares or HHI indexes, together with some structural aspects such as historical reasons and regional integration. In this context, although it is a fact that the German market is less concentrated than the French one, it is also true that the deregulation path is different in each situation: from several regional monopolies to a national market in Germany; and already a single market prior to the liberalization process in France. Path dependencies are also present in the case of Spain and Portugal.

In the Portuguese case, since the interconnection capacity is more or less a quarter of total electricity market dimension, deregulation has brought important competition developments also through the "imported competition" effect. In fact, in addition to the specific structural policies to promote competition in the electricity market, namely in the case of generation licensing diversification, renewable energies promotion and "virtual power plant", (VPP) programs, developments in the Iberian Electricity Market (MIBEL) were of major significance to competition.

\subsection{Innovation in the energy sector}

The analysis of innovation (or R\&D expenditure as a proxy for innovation) in energy must take into consideration a broader perspective on innovation and $R \& D$. This is due to the fact that several technological innovations in other industries or research areas affect positively the energy industry state of the art. Some examples of this situation rely on the computational

\footnotetext{
9 Corresponds to an instrument through which a dominant player (generator) is legally compelled to auction a part of its generation capacity to other market players.

DINÂMI A'CET - IUL, Centro de Estudos sobre a Mudança Socioeconómica e o Território ISCTE-IUL - Av. das Forças Armadas, 1649-026 Lisboa, PORTUGAL

Tel. 210464031 - Extensão 293100 E-mail: dinamia@iscte.pt www.dinamiacet.iscte.pt
} 
sciences or telecommunications developments, which have impact in the processes of dynamic, complex and real-time management of the electricity industry, or in the developments of new materials that enhance the efficiency standards of energy components. Thus, although its extent is hardly measurable, energy industry innovation is positively affected by this spill-over effect of the global innovative efforts.

Therefore, energy specific innovation should be considered in perspective within the global innovation effort in the economy. In general terms, R\&D expenditure in European countries have been increasing in the past two decades: in the EU-27 member states, R\&D expenditure evolved from an average of 1.8\% of GDP in 1995 to 2\% in 2009. Figure 6 shows the evolution of R\&D efforts in some of the EU countries, with Portugal, Spain and Denmark experiencing important growth in the R\&D intensity of the economy, although starting from a lower intensity compared to the EU-27 average. For France, the Netherlands and the United Kingdom the economy intensity in R\&D is either decreasing or stagnant over the period. German and Italian R\&D intensities, although increasing less than in the Iberian countries and Denmark, experienced continuous growth, with Germany reaching 2.8\% of GDP in R\&D expenditure in 2009.

Given this figures and evolution it is fairly acceptable to conclude for an intensification of innovation efforts in the EU as a whole and in some of its member states in particular. In the specific case of Portugal, global R\&D intensity more than tripled between 1995 and 2009.

Figure 6 - R\&D intensity in European countries (all sectors)

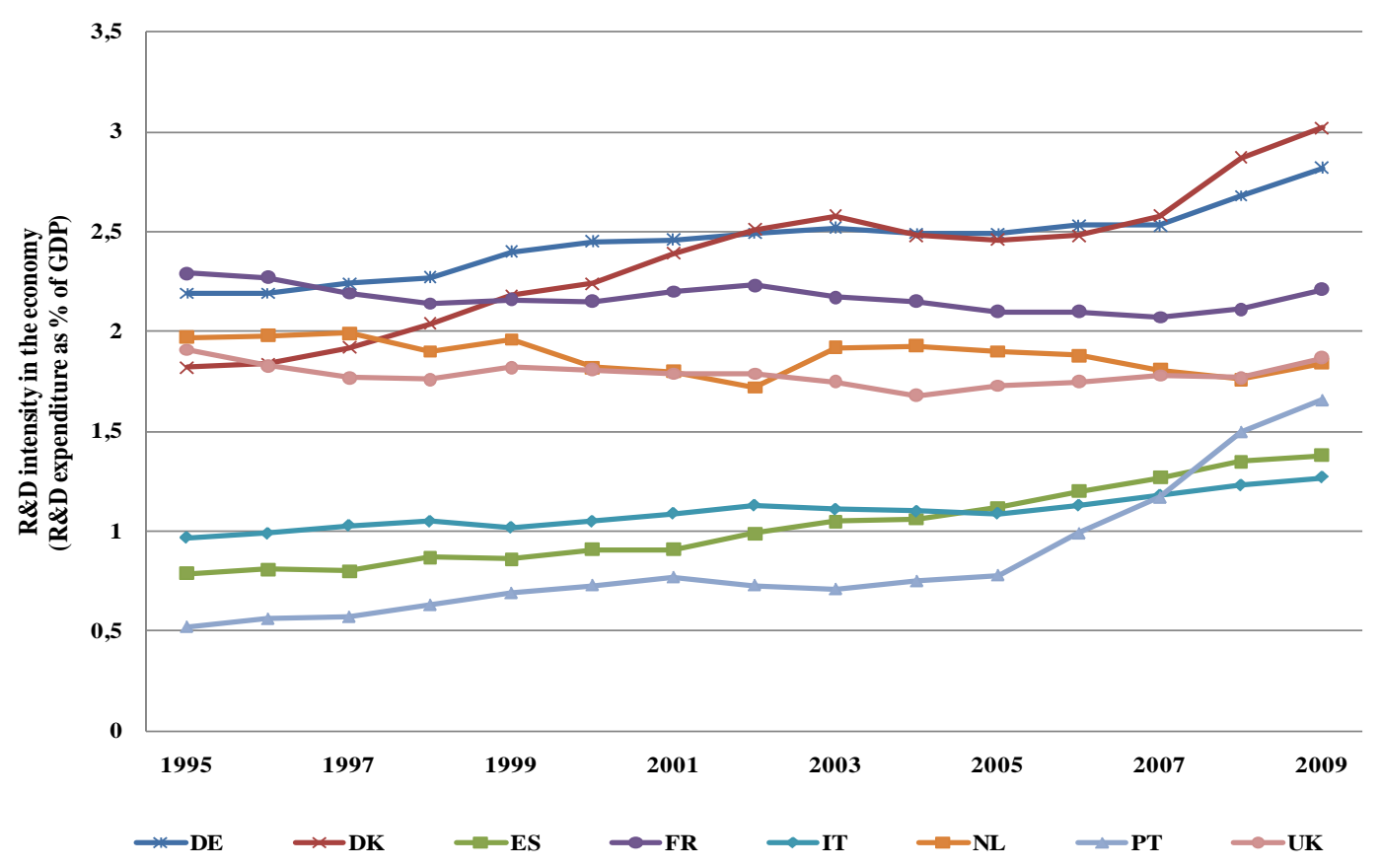

Source: EU DG Research; EUROSTAT. 
In a brief way, we have seen that the $R \& D$ effort has grown since the mid 1990s for the economy as a whole. Due the mentioned spill-over effects of global R\&D expenditure, the energy industry is expected to benefit from that, but it is important to evaluate how the specific energy R\&D effort has evolved in the last two decades. To do that, we will start by using the International Energy Agency (IEA) database on annual energy R\&D budgets for OECD countries, which allows us to analyse energy specific R\&D.

The R\&D budgets for energy comprise several research areas, not all directly attributable to the electricity industry. In this database we may find expenditure in energy efficiency in buildings or fossil fuels' related developments. Since it is difficult to exclude or consider a particular area only, we will take the global value of $R \& D$ in energy in our analysis. Considering the data for the countries analysed above, we have estimated annual index values for each in order to avoid scale effects in the comparison. Figure 7 presents the evolution of $R \& D$ expenditure in the energy sector for the eight countries, with 1990 as the reference year and using the values of IEA database (expressed in 2010 prices and exchange rates when applicable).

Figure 7 shows a declining trend for the R\&D effort in energy, at least for the majority of the analysed individual cases. In fact, apart from the outstanding case of Denmark (and the United Kingdom in the latest two to three years), all remaining countries present a R\&D budget in 2010 which is lower than the 1990s value. Therefore, from this first set of data, we might conclude that the R\&D effort in energy has evolved differently from the rest of the economy: a decline or, at best, a stagnation of specific energy R\&D budgets, comparing with growth in the R\&D intensity of the economy.

Figure 7 - Total R\&D expenditure in the energy industry

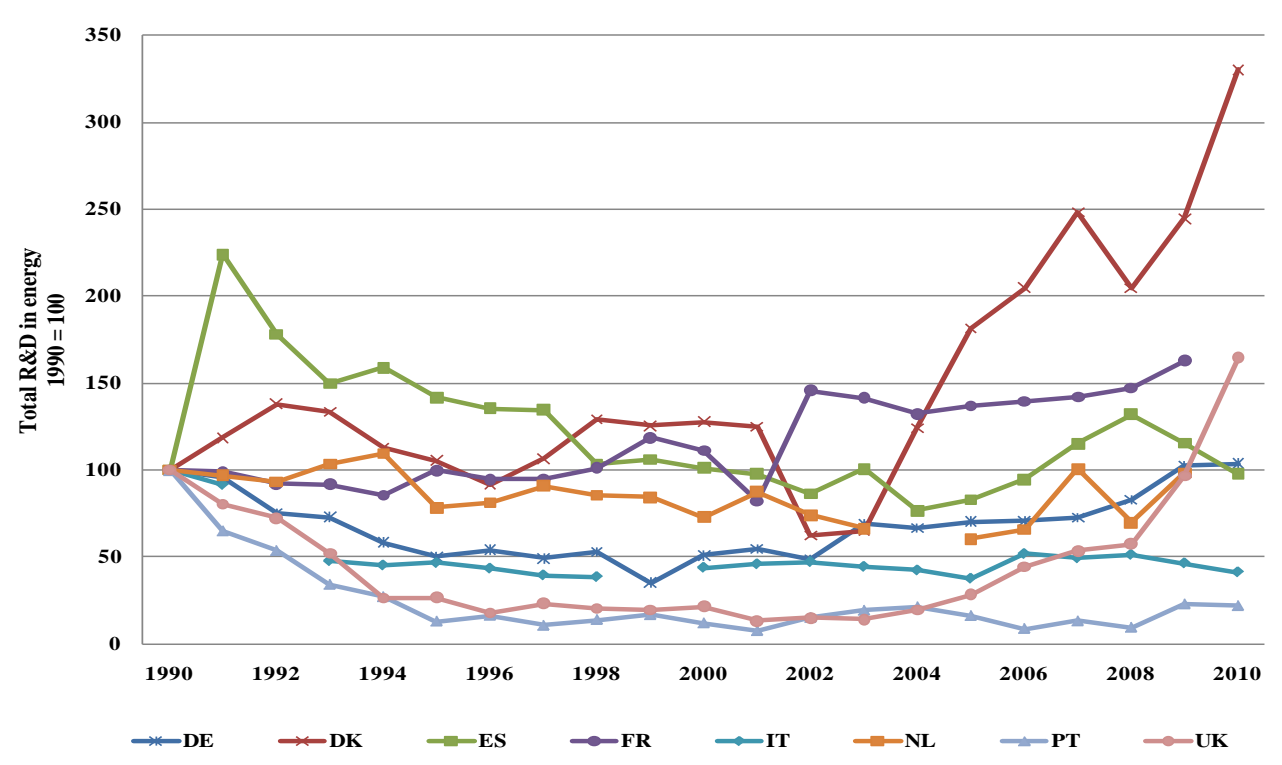

Source: IEA, Energy Technology R\&D Statistics. 
In 2009, the value of energy specific R\&D budgets for the eight countries is barely the same as in 1990, considering the energy sector alone. Countries like Portugal or Italy experienced dramatic cuts in their R\&D budgets and, by the end of the period, Germany only had recovered the 1990's values. As the global primary energy consumption in these countries experienced an average $0.5 \%$ annual growth between 1990 and 2010, the R\&D intensity of energy consumption ${ }^{10}$ declined in this period, e.g., less R\&D investment per unit of energy consumed (Figure 8). The Portuguese experience is even more dramatic, with the value of R\&D expenditure in energy being in 2010 around 13\% of the corresponding value in 1990.

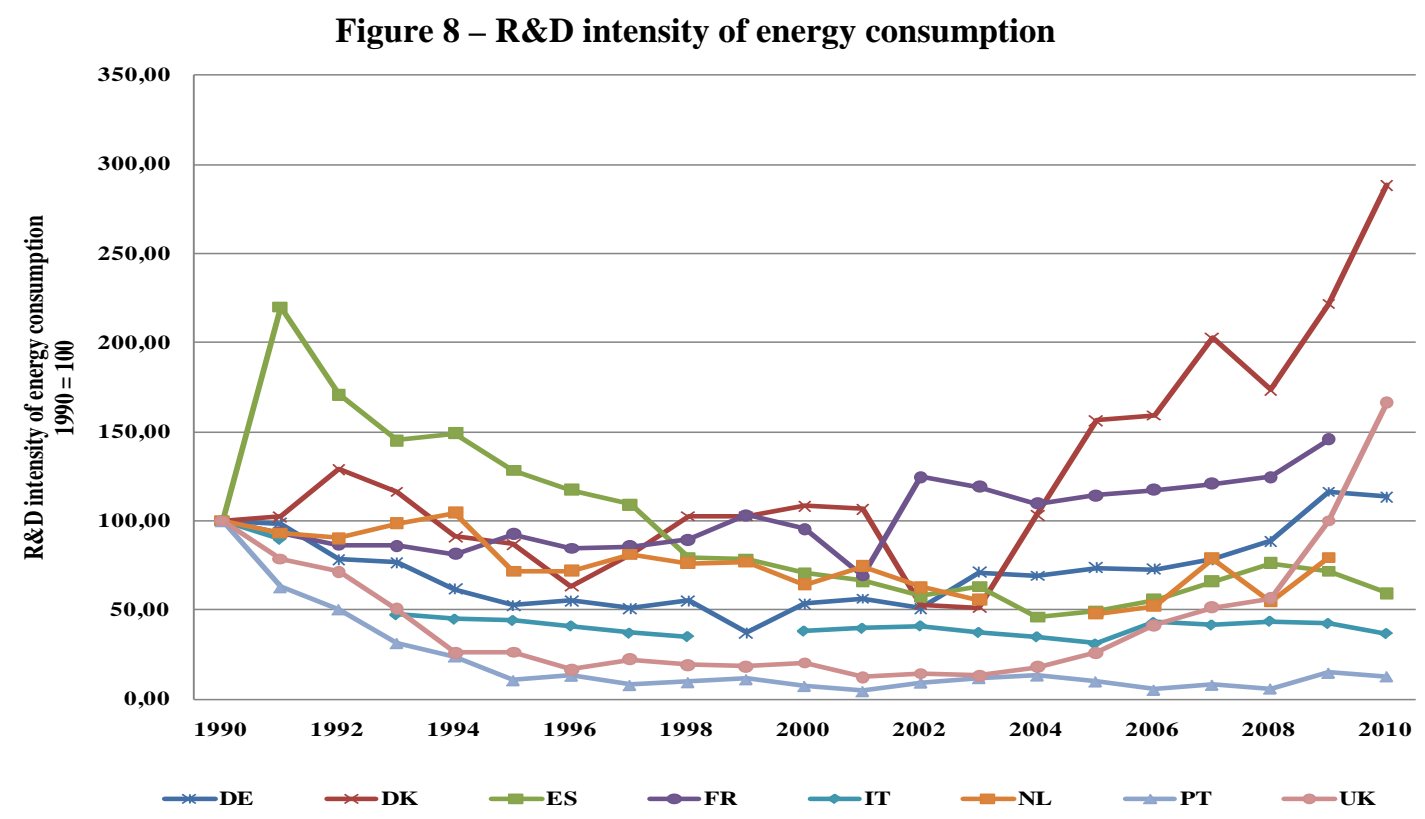

Source: IEA, Energy Technology RD\&D Statistics; authors’ calculations.

The study by Jamasb and Pollitt (2008) had already revealed a cut in the R\&D expenditure of the energy industry. Following the empirical evidence from other authors, Jamasb and Pollitt considered the liberalization processes in the energy industry as a plausible cause for the cuts in R\&D budgets. This assumption relied on the chronological coincidence of the two facts and did not consider any impacts from the spill-over effects deriving from other industries. This situation was observable in the case of the UK, for which the liberalization process was parallel to a dramatic fall in the R\&D intensity of energy consumption.

In any case, and even considering that energy investment in innovation may generate lower returns than in other industries - which could explain the simultaneous growth in the economy R\&D intensity and the decline in specific energy expenditure -, one should consider whether the

\footnotetext{
${ }^{10}$ Ratio between R\&D expenditure and the primary energy consumed in each year. DINÂMI A'CET - IUL, Centro de Estudos sobre a Mudança Socioeconómica e o Território ISCTE-IUL - Av. das Forças Armadas, 1649-026 Lisboa, PORTUGAL Tel. 210464031 - Extensão 293100 E-mail: dinamia@iscte.pt www.dinamiacet.iscte.pt
} 
$\mathrm{R} \& \mathrm{D}$ budget is the most adequate variable to describe the innovation effort in the energy industry and, specifically, in the electricity sector.

Given the emphasis on the support for new and renewable energy sources (RES) in the electricity market, it is plausible to consider the deployment of these technologies as another proxy for the innovation effort in the industry. The joint analysis of the Danish policy for RES promotion, in particular wind generation, and the evolution of R\&D expenditure in this country support the idea of using RES deployment as another descriptive innovation variable in electricity, if we consider Denmark as an example of coordinated and consistent policy for the development of an innovative energy cluster, as suggested by Buen (2005) in his comparison of the Danish and Norwegian wind industries.

The coexistence of different electricity generation technologies implies some extent of economic benchmark between those more mature and extensively tested with the ones in the early stages of development. This is, by definition, a barrier to innovation that specific policies should address in order to encourage the use of new and less competitive energy sources and, thus, overcome youth problems. Sagar and Zwaan (2005) stressed the positive impact of experience obtained with broader use of RES technologies in its economic outcome and investment profitability.

The support given to RES in general, and wind generation in particular, follows more or less the same rationale worldwide: RES are not fully economically competitive with other traditional energy sources such as coal or natural gas for electricity generation, due to scale effects and technology maturity. For this reason, RES policy follows most commonly an approach of providing these technologies with a feed-in tariff and priority dispatch. The value of the feed-in tariff is theoretically set in a level suitable to remove price disadvantages in reaction to other energy sources. Table 3 shows the values of RES support in some of the EU-27 countries, as well as the value of the support per unit of consumption.

Combining the global values of RES support schemes - comprising wind on-shore; wind offshore; hydro; geothermal; and solar PV -, in 2009 (Table 4) with the R\&D budgets for energy, one may find that RES support budgets are clearly above the R\&D expenditure in the energy sector as a whole. In the case of Portugal or Spain, the R\&D budgets in 2009 are a quite negligible part of RES support schemes values (respectively, $0.7 \%$ and $1.3 \%$ ). 
Table 4 - Total expenditure of RES support policies, 2009

\begin{tabular}{|l|c|c|c|}
\hline Member State & $\begin{array}{c}\text { RES-electricity } \\
\text { support expenditure } \\
\text { (million euro) }\end{array}$ & $\begin{array}{c}\text { Gross electricity } \\
\text { consumption } \\
\text { 14 } \\
\text { (Eurostat) } \\
\text { (GWh) }\end{array}$ & $\begin{array}{c}\text { RES-electricity support per } \\
\text { unit of gross electricity } \\
\text { consumed (⿶/MWh) }\end{array}$ \\
\hline Austria & 307 & 69,584 & 4.42 \\
\hline Belgium & 489 & 88,949 & 5.50 \\
\hline Czech Republic & 150 & 68,595 & 2.19 \\
\hline Denmark & 294 & 36,541 & 8.05 \\
\hline France & 556 & 516,455 & 1.08 \\
\hline Germany & 5,618 & 520,968 & 10.78 \\
\hline Great Britain & 1,250 & 378,523 & 3.30 \\
\hline Hungary & 83 & 41,515 & 2.00 \\
\hline Italy & 2,638 & 334,363 & 2.89 \\
\hline Lithuania & 25 & 11,318 & 2.27 \\
\hline Luxembourg & 16 & 7,259 & 12.33 \\
\hline Portugal & 528 & 42,809 & 22.49 \\
\hline Spain & 6,035 & 268,297 & 3.37 \\
\hline Sweden & 478 & 141,884 & 5.46 \\
\hline The Netherlands & 639 & 117,119 & \\
\hline
\end{tabular}

Source: CEER (2011), Council of European Energy Regulators, Report on Renewable Energy Support in Europe, p.11.

Note: RES comprise wind on-shore; wind off-shore; hydro; geothermal; and solar PV.

As a result of RES promotion policies, wind generation $t$ grew significantly in the analysed countries over the past decade. In the case of wind energy, the most significant of RES in terms of unexplored large scale potential ${ }^{11}$, Figure 9 shows a significant growth in wind generation contribution to gross consumption in Denmark, Spain, Portugal and Germany.

Apart from the Danish case, the countries in which the wind generation has grown more significantly are the same for which we have observed an overall tendency of declining energy R\&D expenditure. In the case of the UK, it is observable not only an overall declining tendency in $R \& D$ expenditure but also that the wind generation contribution to consumption is low.

\footnotetext{
${ }^{11}$ Although considered as a renewable energy source, large hydro generation facilities are considered as traditional electricity generation technology and are commonly outside the scope of RES promotion policies. In some cases, small hydro is supported through RES schemes due to its characteristics of capital intensive investment and renewable and endogenous energy source.
}

DINÂMIA'CET - IUL, Centro de Estudos sobre a Mudança Socioeconómica e o Território ISCTE-IUL - Av. das Forças Armadas, 1649-026 Lisboa, PORTUGAL

Tel. 210464031 - Extensão 293100 E-mail: dinamia@iscte.pt www.dinamiacet.iscte.pt 
Figure 9 - Wind generation contribution to electricity consumption

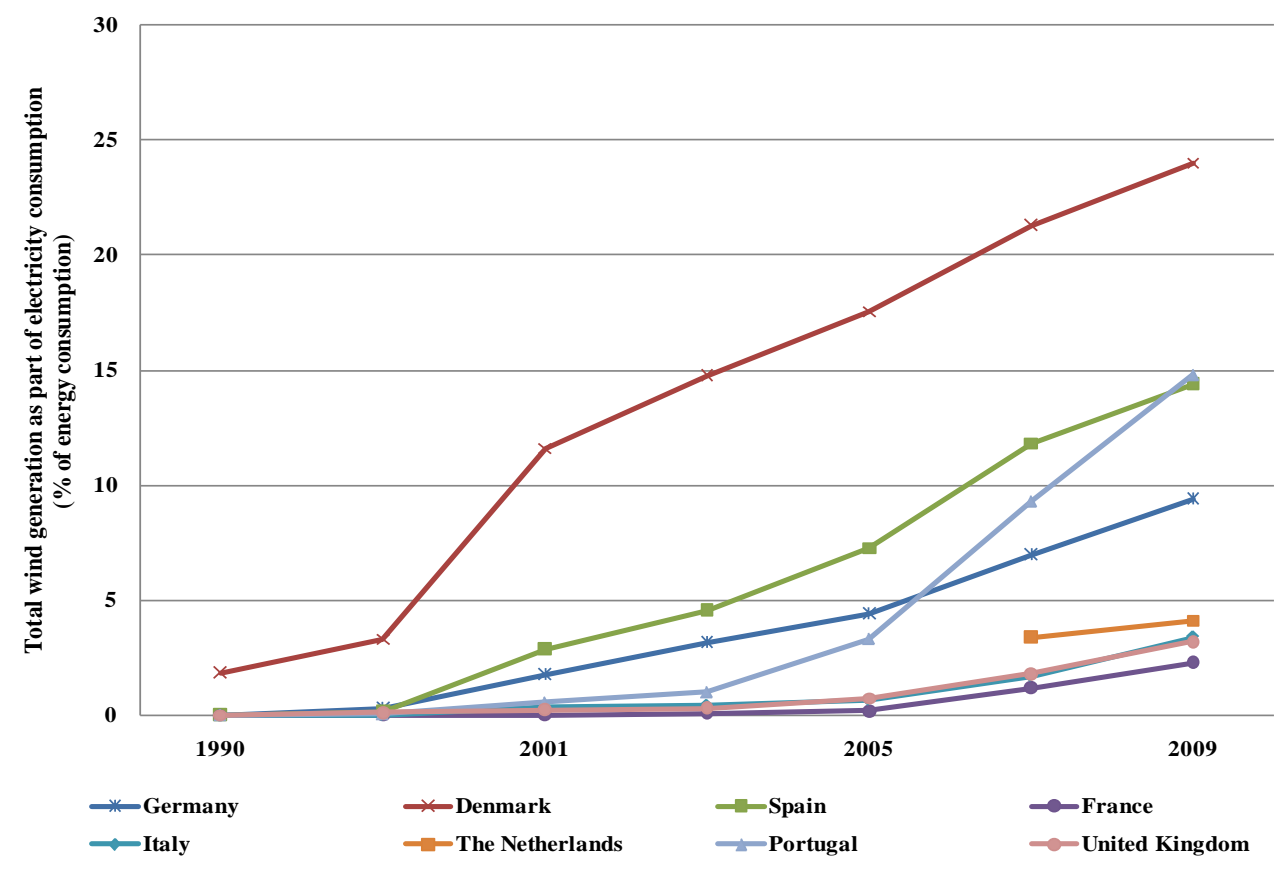

Source: EWEA.

The Danish example, for which we find simultaneous growth in R\&D effort and RES penetration, is fairly explained by the country's option to promote an energy industrial cluster around the wind generation industry, extensively described by Buen (2005). In the case of Spain, Germany and, more noticeably, Portugal, RES promotion policies seem to be a substitute for R\&D expenditure, given the chronological coincidence of declining R\&D budgets and RES deployment.

\subsection{Innovation and competition results in perspective}

Empirical evidence from the innovation and competition policies in the selected European countries has provided some basic ideas that can be summarized as follows:

1 - Despite a global continuous growth, R\&D in the energy sector has been declining for more than a decade;

2 - Beneficiary spill-over effects are present in the energy industry in what regards innovation in other industries;

3 - RES support schemes, highly motivated by technologies' youth, involves important amounts of investment and in some cases, such as Portugal or Spain, are more than 100 times the total budget for $R \& D$, leading to the idea of a substitution effect between $R \& D$ expenditure and RES support investments; 
4 - Combining the values for RES support schemes and explicit R\&D budgets, the innovation effort in the electricity industry not only did not decline throughout the last two decades but has even experienced a major increase;

5 - Competitive pressure in selected European countries' electricity markets has evolved in a quite diffuse way, with significant improvements in terms of legal and formal liberalization but incipient degrees of retail competition;

6 - Competition in wholesale electricity markets has experienced some improvements, but these are far more attributable to regional market integration than to effective entry of new players.

In countries such as Spain or, more interestingly for this paper, Portugal, positive results in terms of competition developments were accomplished simultaneously with a decisive option for RES promotion. Namely in the case of Portugal, higher competitive pressure arising from an increased market integration did not prevent a significant improvement in the deployment of RES and, more particularly, wind generation. This relationship between the two policy axes seems to be attributable more to objectives' alignment rather to explicit policy coordination. In fact, deployment of new RES not only is contributing to technology diversification but is also promoting lower primary energy dependency (and, by this, security of supply) along with licensing new market participants.

In the case of the UK, there is no evidence of a simultaneous increase in competition and decline in innovation effort. In fact, although explicit R\&D budgets have declined for over a decade (and inverted the tendency in the last three years) and cumulatively RES deployment is not outstanding, competitive pressure seems to be either the same or lower in the present compared to the early 2000s. As an important background to both the energy sector specific policy and the innovation policy, the emergence of an environmentally sustainable energy system is a feature which most policies have to take into account. In fact, environmental and climate changes concerns are present both in the explicit R\&D effort (investment in energy efficiency and green technologies) and sector-specific policies such as energy source diversification and security of supply (given the finite characteristic of fossil fuels). 


\section{MAIN CONCLUSIONS}

This paper is focused on the role played by public policies' coordination in shaping a new industry model, namely the electricity market, which calls for a low carbon economy along with a competitive and an innovative energy industry. Both policies were analysed using proxies: competition policy was assessed through ex-ante structural changes brought by the liberalization process rather than those in the traditional scope of competition regulation (ex-post or behavioural approach); less representative budgets in $R \& D$ in energy induced the use of renewable primary energy sources, which relative weight in the fuel mix is taken as a proxy for sector specific innovation policy.

A first concluding remark relies on the fact that explicit coordination of both energy sector policy and innovation policy is positive for economic and environmental sustainability, as recently acknowledged in policy formulation in Europe (2020 Strategy).

Taking separately competition and innovation policies in the energy industry, some tendencies were clearly identified, either for Portugal or for EU as a whole. In terms of industrial organization, liberalization attained a significant success in terms of vertical unbundling of generation and retailing activities, at least in terms of formal separation of activities. However, horizontal market concentration remains high and there is strong evidence that vertical strategies have hindered better results through competition, along with the fact that new entrants are often incumbents in other domestic markets.

In what concerns innovation policy, evidence shows decreasing R\&D budgets in the industry, with few exceptions across Europe (Denmark). Decreasing R\&D budgets are also a feature of companies' activity, partially compensated by research institutions. Nevertheless, once the investment in renewables production was considered as a proxy of innovation indicators, there is an impressive progress in terms of market penetration of those energy sources, particularly in the Portuguese case.

National results suggest the existence of three main cases: (i) long term policy coordination in the case of Denmark; (ii) diffuse evidence of detrimental developments in innovation due to liberalization in the case of UK; and (iii) implicit goal alignment for competition and innovation policies in the case of Spain and Portugal.

As for the case of Denmark, public policies were designed to promote a wind energy cluster, giving priority to this objective and implementing the deregulation process as a consequence of the EU single market objective. Accordingly, the competitiveness of the economy is reinforced by a value-added industrial cluster, which contributes to lower energy dependency and structural energy policy became part of broader policy options. 
In the case of the UK, Jamaasb and Pollitt (2008) have already highlighted the chronological coincidence of declining $R \& D$ in energy and the liberalization process. Nevertheless, the competitive available indicators don't clearly demonstrate significant improvements and, therefore, main results from both policies do not confirm nor refute the idea of negative impacts of liberalization processes on the innovation effort. One should not exclude a possible negative impact on R\&D effort of the market participants’ perception of the liberalization challenges and market contextual conditions.

Finally, the case of Portugal (and also Spain), seems to indicate a slower pace of liberalization in the beginning of the process, but increased competitive pressure (even in the case of competition derived from regional market integration) did not avert a significant effort in new technologies deployment, although both policy axes weren't explicitly coordinated. This result was probably positively impacted by a significant objective alignment in each policy axis as above mentioned.

In the case of Portugal it is also important to observe that license diversification concerns in the RES promotion policy have actively contributed to decreasing market concentration in electricity generation, showing some positive impact of innovation on competition. In any case, this single evidence alone does not confirm the inverted U- shaped relationship between innovation effort and competitive pressure, but gives compelling signals that policy coordination, at least in terms of global objectives, may contribute to explore the positive relationship of those two policy axes and, thus, implement a new energy model. 


\section{REFERENCES}

Artés, J. (2009), “Long-run versus short-run decisions: R\&D and market structure in Spanish firms”, Research Policy, 38, 120-132.

Barker, T., Ekins, P., Foxon, T. (2007), “The macro-economic rebound effect and the UK economy”; Energy Policy, 35, 4935-4946.

Buen, J. (2005), "Danish and Norwegian wind industry: The relationship between policy instruments, innovation and diffusion”, Energy Policy, 34, 3887-3897.

Cambridge Economic Policy Associates (2004), Study on Electricity and Gas Markets in Portugal, Lisboa, Portuguese Competition Authority.

CEER - Council of European Energy Regulators (2011), CEER Report on Renewable Energy Support in Europe, Brussels, May 2011.

Costa, C., Rovere, E., Assmann, D. (2008), "Technological innovation policies to promote renewable energies: Lessons from de European experience for the Brazilian case”; Renewable \& Sustainable Energy Reviews, 12, 65-90.

EC-DG ENER, "Report on progress in creating the internal gas and electricity market”; 2005, 2007, 2008 and 2009-2010 editions.

DG Research (2009), Science, Tecnology and Competitiveness - Key Figures Report 2008/2009.

DG TREN (2007); “EU Energy Policy Data” - SEC (2007) 12.

EC (2011), 2009-2010 Report on progress in creating the internal gas and electricity market. Commission Staff Working Document, Brussels, June.

European Environment Agency, Public Database.

Fagerberg, J., Mowery, D., Nelson, R., orgs. (2004), The Oxford Handbook of Innovation, Oxford, Oxford University Press

Foxon, T., Grossa, R., Chaseb, A., Howesb, J., Arnallc, A., Anderson, D. (2004), "UK innovation systems for new and renewable energy technologies: drivers, barriers and systems failures”, Energy Policy, 33, 2123-2137. 
Foxon, T., Pearson, P. (2006), “Towards improved policy processes for promoting innovation in renewable electricity technologies in the UK”, Energy Policy, 35, 1539-1550.

Gallagher, K.S., Holdren, J.P., Sagar, A.D. (2006), “Energy-Technology Innovation”, Annual Review of Environment and Resources, 31, 193-238.

Gan, L., Eskeland, G., Kolshus, H. (2007), “Green electricity market development: Lessons from Europe and the US”, Energy Policy, 35, 144-155.

Godoe, H., Nygaardb, S. (2005), “System failure, innovation policy and patents: Fuel cells and related hydrogen technology in Norway 1990-2002”, Energy Policy, 34, 1697-1708.

Herring, H., Roy, R. (2006), “Technological innovation, energy efficient design and the rebound effect”, Revised paper for Technovation, November 2006.

International Energy Agency, Energy R\&D Statistics.

Jamasb, T., Pollitt, M. (2008), "Liberalisation and R\&D in network industries: The case of the electricity industry”, Research Policy, 37, 995-1008.

Kahn, A. (2005), The Economics of Regulation, Cambridge, Mass., MIT Press.

Markard, J., Truffer, B. (2006), "Innovation processes in large technical systems: market liberalization as a driver for radical change?”, Research Policy, 35, 609-625.

Marques, V. (2003), Poder de mercado e regulação nas indústrias de rede, Lisboa, Gabinete de Estudos e Prospectiva Económica do Ministério da Economia.

Moore, M., Arent, D., Norland, D. (2006), “R\&D advancement, technology diffusion, and impact on evaluation of public R\&D”, Energy Policy, 35, 1464-1473.

Nakada, M. (2005), "Deregulation in an energy market and its impact on R\&D for low carbon energy technology”, Resource and Energy Economics, 27, 306-320.

Nardi, P. (2010), “Transmission Network Unbundling and Grid Investments: Evidence from the UCTE Countries”, Available at Social Science Research Network, http://ssrn.com/abstract=1622733.

Noaillya, J., Batrakovab, S. (2010), "Stimulating energy-efficient innovations in the Dutch building sector: Empirical evidence from patent counts and policy”, Energy Policy, 38, 78037817. 
Energy, competition and innovation: how policies' coordination may contribute to a new energy model

Sagar, A., Zwaan, B. (2006), "Technological innovation in the energy sector: R\&D, deployment, and learning-by-doing”, Energy Policy, 34, 2601-2608.

Shepard, W.G. (1997), The Economics of Industrial Organization, $4^{\text {th }}$ Edition, Portland, OR, Prentice-Hall International.

Tsoutsos, T., Stamboulis, Y. (2005), "The sustainable diffusion of renewable energy technologies as an example of an innovation-focused policy”, Technovation, 25, 753-761.

Vidil, R., Marvillet C. (2005), “The innovation process in the energy field”, Energy, 30, 12331246.

Vives, X., (2008), “Innovation and competitive pressure”, The Journal of Industrial Economics, 56, 3, 419-469. 